\title{
A Preliminary Report on the Use of Bench-Top X-Ray Micro-Computerised Tomography to Study the Malpighian Tubules of the Overwintering Seven Spotted Ladybird Coccinella septempunctata L. (Coleoptera: Coccinellidae)
}

\author{
Duncan Bell, ${ }^{1}$ Lewis Woolnough, ${ }^{2}$ David Mortimore, ${ }^{3}$ Nick Corps, ${ }^{4}$ \\ Diana M. Hudson, ${ }^{5}$ and Mark K. Greco ${ }^{6,7}$ \\ ${ }^{1}$ East Anglian Radiography Research, Modelling and 3D Printing Group, School of Science, Technology and Health, \\ University Campus Suffolk, Ipswich IP4 1QJ, UK \\ ${ }^{2}$ Quekett Microscopical Club c/o, Natural History Museum, Cromwell Road, London SW7 5BD, UK \\ ${ }^{3}$ Newbourne Solutions Ltd., Newbourne, Woodbridge IP12 4NR, UK \\ ${ }^{4}$ e2V. Scientific Instruments Ltd., Sirius House, Watery Lane, High Wycombe, Bucks HP10 0AP, UK \\ ${ }^{5}$ Department of Biology, Wycombe Abbey School, High Wycombe, Bucks HP11 1PE, UK \\ ${ }^{6}$ Department of Biology and Biochemistry, University of Bath, Bath BA2 7AY, UK \\ ${ }^{7}$ INVERT Group, Department of Electrical and Electronic Engineering, University of Bath, Bath BA2 7AY, UK
}

Correspondence should be addressed to Mark K. Greco, m.k.greco@bath.ac.uk

Received 4 January 2012; Accepted 16 March 2012

Academic Editor: Subba Reddy Palli

Copyright (C) 2012 Duncan Bell et al. This is an open access article distributed under the Creative Commons Attribution License, which permits unrestricted use, distribution, and reproduction in any medium, provided the original work is properly cited.

\begin{abstract}
The application of micro-CT scanning techniques on a small sample of "Seven-spot ladybirds" Coccinella septempunctata, collected in December 2009, identified an accumulation of material with a very high, relative X-ray attenuation value in the malpighian tubules of most but not all of the individuals sampled. The passage of metals such as cadmium in soil through a food chain to finally accumulate in high concentrations in ladybirds and lacewings has been previously reported. The identification of the dense material found in our sample of ladybirds, its origin, and the process by which it accumulates in, and is processed by, the malpighian tubules is the challenge ahead. The authors speculate that a straightforward means of monitoring levels of metallic pollutants in the environment might emerge.
\end{abstract}

\section{Introduction}

$\mathrm{X}$-ray Computerised Tomography (X-ray CT) as well as $\mathrm{X}$-ray micro-Computerised Tomography (X-ray micro-CT) are being increasingly used to study both insect colony behaviour [1-6] and also anatomy of individual insects [711]. One of us (MKG) has coined the phrase "Diagnostic Radioentomology" (DR) to describe such studies [7].

We set up and then used a small, relatively inexpensive Skyscan Bench-top micro-XT scanner (Skyscan 1174 microCT) from 22nd December 2009 to 5th January 2010 to study a small number of overwintering ladybird beetles, Coccinella septempunctata L. (Coleoptera: Coccinellidae). The microCT images showed that the lining of the malpighian tubules of several of the C. septempunctata appeared to contain a dense, radio-opaque material.

As nicely summarised by Wigglesworth in his excellent monograph of Insect Physiology in the chapter on excretion [12], "The malpighian tubules still remain unquestionably the chief excretory organs. The malpighian tubules are relatively simple tubular glands which open at the junction of the mid-gut and the hind-gut. They are exceedingly variable in form: sometimes being numerous (e.g., 100) and short, sometimes few in number (e.g., 2) and long; sometimes simple and sometimes branched; occasionally anastomosing to form closed loops; while sometimes more than one type may be present. Their histological structure is no less variable. Usually their epithelial cells bear a striated border, 
but this may be wanting. Many histological changes have been described in the active cells of the malpighian tubes: the discharge of vesicles, the eruption of vacuoles, and so forth. It is not improbable that more than one cytological mechanism of excretion may exist; but certainly many of the recorded observations are artefacts."

Of direct relevance to the present study (please see below) was the observation of Marcus, that many beetles "phytophagous, carnivorous and omnivorous species as well as those that feed on dry substances have the distal part of their malpighian tubules closely investing the rectum, being surrounded to it by a delicate membrane" [13] and for illustration see [12, page 66]. Further work on this topic in the 1960s and 1970s, particularly that of Maddrell and colleagues, was particularly key [14]. The nature of the socalled "cryptonephridial" condition was further discussed and illustrated in Imms' General Textbook of Entomology in 1977 [15, page 249]. About the same time, one of us $(\mathrm{DMH})$, as part of her $\mathrm{PhD}$ thesis [16], and in subsequent publications $[17,18]$ summarised the then known anatomy and physiology of insect malpighian tubules with particular emphasis on those of Locusta migratoria L. (Orthoptera: Acridoidea). For relevant recent references up to the present time on studies of insect malpighian tubules, see $[19,20]$ and the reference they contain in their "Excretory System" Chapters.

This paper reports on the X-ray micro-CT appearances of 10 overwintering [21] C. septempunctata with particular reference to their malpighian tubules and also includes a dissecting light microscopy examination of a further $5 \mathrm{C}$. septempunctata to confirm that the structures highlighted by micro-CT were indeed the insects' malpighian tubules. Also, the possible nature of the dense, radio-opaque material found in some of the ladybirds' malpighian tubules is discussed.

\section{Materials and Methods}

2.1. The Insects and Traditional Dissection Techniques. Ten specimens of overwintering C. septempunctata were euthanised on the 23rd of December 2009 by placing in a deep freezer $\left(-20^{\circ} \mathrm{C}\right)$ for 12 hours and then stored in $70 \%$ ethanol until scanned using the Skyscan $1174 \mathrm{X}$-ray microCT (see below). Before euthanising, the overwintering $C$. septempunctata were situated on the South-facing side of the inside of a poorly fitting wooden window frame of one of our houses (GDB). The house is set in a rural village in Suffolk, East Anglia, UK, surrounded by agricultural land $\left(52^{\circ} \mathrm{N}: 1^{\circ} 35^{\prime} \mathrm{E}\right)$.

An additional five non-overwintering C. septempunctata were collected in September 2011 by (LW) from his garden near Bury St. Edmunds in Suffolk $\left(52^{\circ} 15^{\prime} \mathrm{N}: 00^{\circ} 4^{\prime} \mathrm{E}\right)$ and were subjected to dissecting light microscopy examination after euthanising using ethyl acetate.

2.2. Examination of C. septempunctata by Traditional Dissection Techniques. One of us (LW) aided by a dissecting light microscope as described elsewhere [22] performed abdominal dissections of the malpighian tubules of five
C. septempunctata in the non-overwintering state that had been collected in September 2011. There were 2 female and 3 males.

2.3. X-Ray Micro-CT Technique. A Skyscan 1174 Desktop $\mathrm{X}$-ray micro-CT scanner was set up by using the sample scanning, reconstruction, analysis, and visualization $(2 \mathrm{D}$ and 3D) methodology and protocols according to Tarplee and Corps [23], which also contains useful guidelines, notes, and selected references on micro-CT scanning.

The ladybird samples were contained in plastic tubes and scanned at several different energy levels varying from 30 to $50 \mathrm{kV}$ with and without the addition of a topically applied iodinated radiographic contrast agent (Omnipaque). 180 degree scans with an angular rotation step of 0.5 degrees were used. The results of using dual energy algorithms and the effect of applying such radio-dense material to the exterior of the insect's exoskeleton are beyond the scope of this paper and will be reported in a separate paper. However, for the present study, tomographic reconstruction of the transmission X-ray images from the $50 \mathrm{kV}$ dataset using the Skyscan NRecon software produced 184 transverse/axial slices of $1024 \times 1024$ pixels, which were saved as 16 bit TIFFs. The pixel resolution in $X, Y$, and $Z$ (inter-slice) directions was $9.86 \mu \mathrm{m}$.

2.4. Software for Viewing the 3D Micro-CT Data. We used both the Skyscan in house software, see [23], as well as the "Disect" viewing software (http://www.disectsystems.com/) for viewing the 2- and 3D data as described and illustrated with various training videos on the "Disect website." The Malpighian tubules were masked, segmented, and cropped using the commercially available software, TomoMask (http://www.tomomask.com/).

\section{Results}

3.1. Traditional Dissection. The first two dissections turned out to be female $C$. septempunctata with their abdomens containing eggs. In each case, removal of the abdominal section of the alimentary tract revealed the presence of what appeared to be two sets of malpighian tubules with the proximal ends of each set attached to the gut. Neither of these two sets of tubules had the form of gastric caecae found in some insects (which tend to originate near the distal portion of the crop, are relatively short, are of greater diameter than a malpighian tubule, and essentially resemble a fold in the gut wall [24]).

The next dissection was a male specimen. Removal of the elytra, posterior wings, and dorsal tergites revealed welldeveloped fat bodies (Figure 1). By carefully teasing away of the surrounding soft tissue, the complete lengths of two of the malpighian tubules were revealed (Figure 2). It is clear from the two photomicrographs shown (Figures 1 and 2) that each malpighian tubule forms a complete loop; attachment at the anterior end is around the junction of the mid gut and ileum (i.e., hind gut), whilst the posterior end appears closely attached to the lower alimentary tract. 


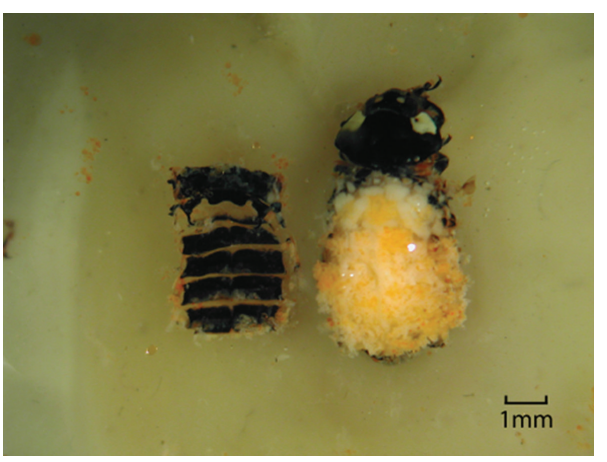

Figure 1: Photomicrograph of "stage 1" dissection of C. septempunctata with elytra and tergites removed which enabled in situ visualization of the dorsal aspect of gross internal anatomy.

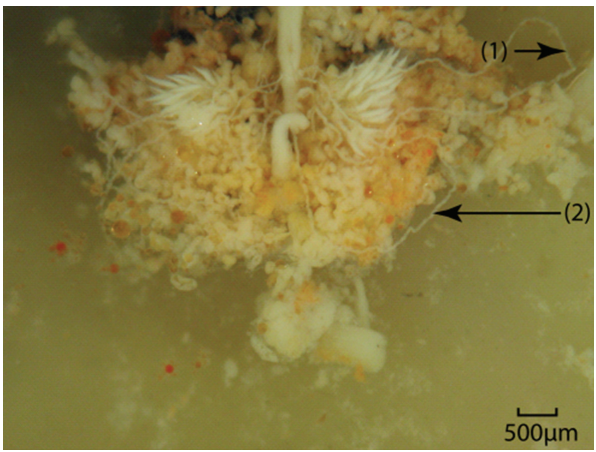

FIgure 2: Photomicrograph of "stage 2" dissection of C. septempunctata detailing the abdominal portion of the alimentary tract. Two complete malpighian tubules (1) and (2) were physically unfolded for improved examination.

Figures 3 and 4 show a further photomicrograph and diagram of specimen 4 in which the thoracic and abdominal section of the alimentary tract have been removed. In total, there appear to be six individual malpighian tubules in $C$. septempunctata.

\subsection{Micro-CT Image Appearances and Their Software Manip-} ulation. Figures $5,6,7$, and 8 show various views of some of the male and female overwintering C. septempunctata specimens scanned, while Figure 8 shows just the malpighian tubules after the use of Tomomask to segment out the radioopaque malpighian tubules.

A rough indication as to the relative density of the material in the malpighian tubules when compared with (say) the ladybird's exoskeleton or internal organs can be illustrated by the "Advance" feature of the "window and levelling tool of "Disect", where higher gray scale values indicate more X-ray absorption by a denser material. When using the 16 bit TIFF data loaded into "Disect", the degree of radio-opacity can be viewed on a histogram on a scale of $0-65,536$. By making the "window size" just 1 unit wide and "levelling" up and down (i.e., effectively binarising the data), one can see when a particular structure either first begins to appear or conversely when it starts to disappear

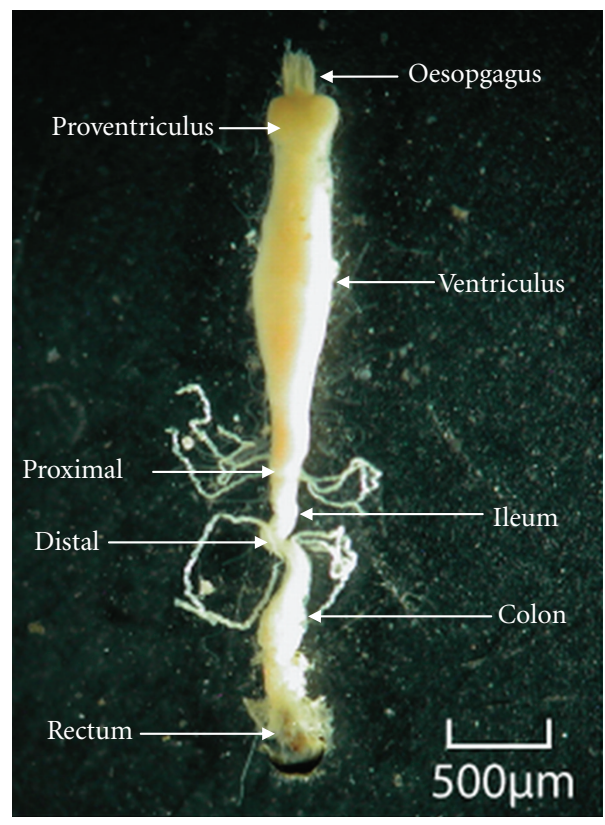

Figure 3: Photomicrograph of the resected thoracic and abdominal sections of the alimentary tract of C. septempunctata, with proximal and distal ends of the malpighian tubules attached.

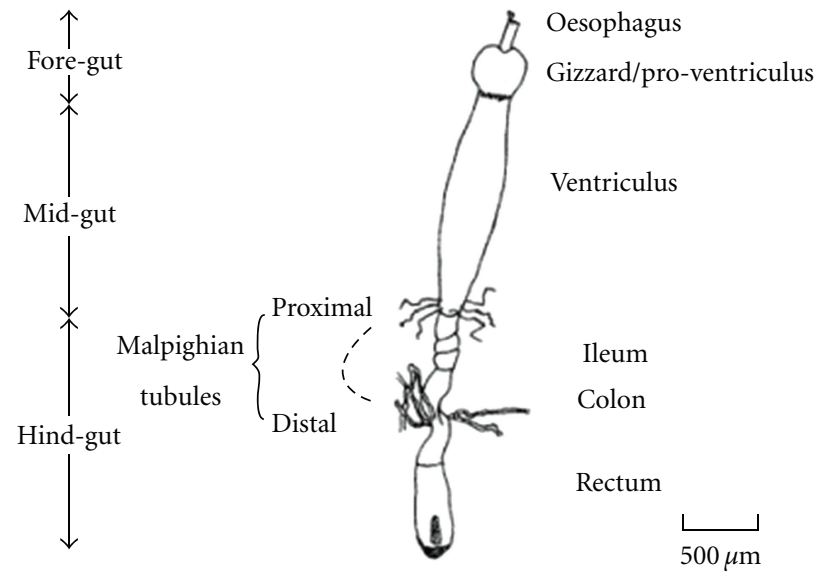

Figure 4: Schematic diagram of thoracic and abdominal sections of the alimentary tract of C. septempunctata.

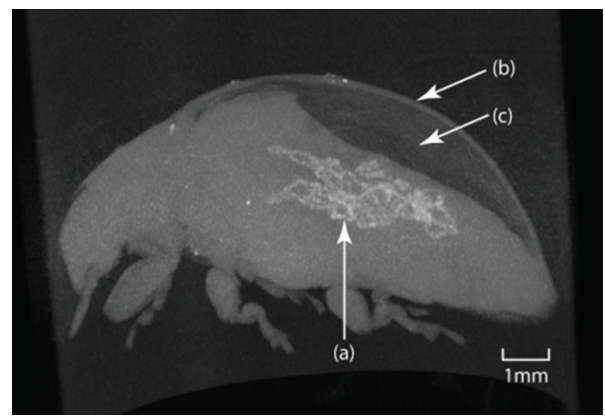

Figure 5: A 3D, volume rendered, micro-CT image of a male C. septempunctata using Maximum Intensity Projection (MIP) showing (a) radio opaque malpighian tubules, (b) elytra, and (c) folded wings in the air space between elytra and tergites. 


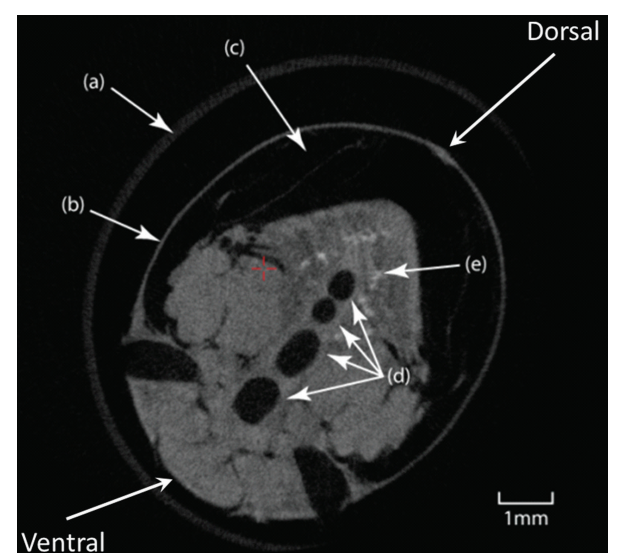

Figure 6: A 2D micro-CT image showing a transverse section through a C. septempunctata abdomen with details of (a) wall of plastic tube-mount, (b) elytra, (c) air space containing folded wings between elytra and dorsal tergites, (d) air sacs, and (e) malpighian tubules.

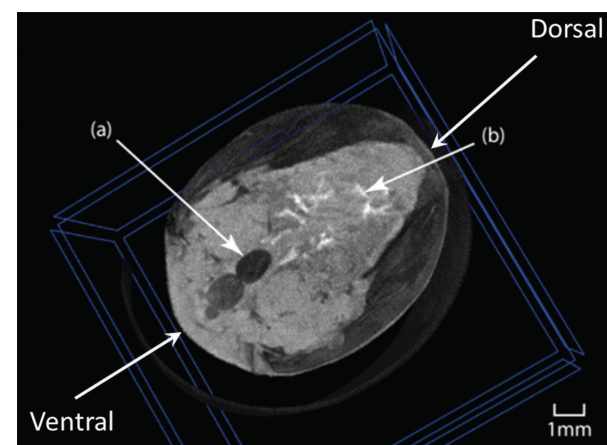

Figure 7: A 2D micro-CT image showing a transverse section through a $C$. septempunctata abdomen showing (a) nondense "black" radio-lucent air-sacs and (b) dense "white" radio-opaque malpighian tubules. Blue lines indicate the selectable cutting planes.

as one levels up from 0 upwards: thereby obtaining a range estimate. Using the data illustrated (Figure 6), the range of values were 6,930-14,000 for the plastic tube, $12,770-21,760$ for the elytra, 13,860-30,400 for the internal organs, and from 34,000 to 44,870 for the radio-opaque material in the malpighian tubules. These values demonstrate that microCT gray scale (density) data can be useful in diagnosing, segmenting, and studying insect malpighian tubules.

In agreement with the dissection and photomicrograph results, the micro-CT data suggest that there are 6 malpighian tubules and that they are of the cryptonephridial in type.

\section{Discussion}

The micro-CT results in the overwintering seven spotted ladybird; C. septempunctata clearly showed that the malpighian tubules contain an unknown extremely radioopaque material. The fact that there were six such structures with the distal ends in close contact with the rectum is

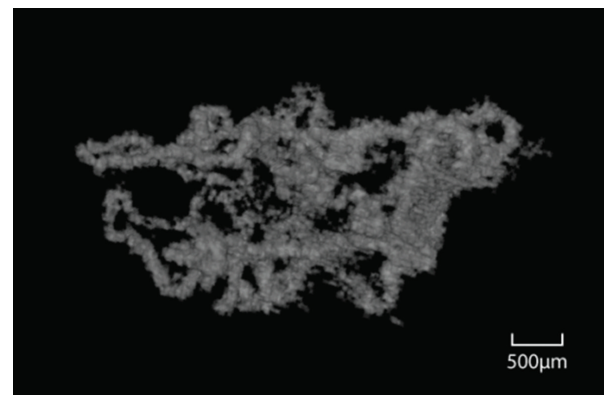

Figure 8: A 3D, volume-rendered and segmented image of the radio-opaque malpighian tubules in C. septempunctata.

in close agreement (a) with our finding at dissecting light microscopy and (b) the available literature that suggests that most polyphagic coleopterans such as ladybirds have cryptonephridial malpighian tubules [12-20, 24].

Various authors stress how highly variable are both the number of malpighian tubules and the histological appearance of the tubular lining cells in different regions of the tubule. That the proximal ends of the tubules enter the gut between the mid and hind gut is not in doubt as shown elegantly (for instance) by scanning and transmission microscopy $[16,17]$. Sometimes the proximal end of each individual malpighian tubule enters the gut separately while in some several malpighian tubules will join a common ureter before entering the gut.

The received wisdom is that the distal ends of the malpighian tubules are "blind-ended" even when the distal ends are in close association with the rectum [12-20, 24]. Having said this, Imms shows in one of his diagrams of the malpighian tubules of a Bloody-nosed beetle, Timarcha tenebricosa Latrielle (Coleoptera: Chrysomelidae), a cryptonephridial looping distal end but with the lumen of each tubule clearly being continuous with that of the gut at both ends [15]. More recent studies [20, pages 437-439] have suggested this may be an artifact and that in fact in all insects with a cryptonephridial system in which the distal ends of the tubules are enveloped within a membrane and held close to the surface of the rectum, but that the tubules do not penetrate the lumen of the rectum but rather lie on the outer surface of the rectum within a perinephric chamber bounded by the perinephric membrane. In our opinion, further studies are clearly required in the case of $C$. septempunctata, which will require a combination of micro$\mathrm{CT}$, light microscopy, and electron microscopy.

Further, more detailed studies are also required to elucidate (a) the nature of the radio-opaque material we have demonstrated in the overwintering C. septempunctata malpighian tubules and (b) clarify if this phenomenon is confined to just this species of ladybird or whether it is a common phenomenon in other beetle species. At the present time, we can only speculate as to what the radioopaque material might be. It is so radio-opaque that it must contain a significant amount of some metal compound such as calcium, magnesium, or (as in the case of the locusts' mandibles) zinc [8]. 
On reviewing the literature on ladybird malpighian tubules, we came across a reference to the detection of cadmium-containing compounds [25] in these insects. The authors postulate that possibly cadmium salts were somehow in the soil as a result of fertilising the fields with unprocessed or poorly processed waste material. They further postulated that the cadmium in the soil was then taken up by plants, which in turn could get into phytophagous sap-sucking insects such as aphids, which in turn could then be ingested by ladybirds. If so then the ladybird could be at the top of a food chain for cadmium accumulation and thus monitoring its presence and concentration in ladybirds might be potentially of value. The same authors have subsequently reported a similar phenomenon when the lacewing rather than the ladybird is the insect consuming the aphids [26].

In this study, we have shown that with a relatively inexpensive X-ray bench-top micro-CT scanner, excellent images with high resolution can be obtained [23]. We found that "Disect" viewing software was easy to learn $[27,28]$ and also had the added benefit of sharing micro-CT data across the world if ever required [29-34].

The use of the Tomomask software greatly speeded up and simplified the process of masking, segmenting, and cropping data CT data stacks whether they are in the form of DICOMs or (as is more normal with micro-CT data) stacks of TIFFs, JPEGs, JEG 2000, BMPs or PNGs.

\section{Conclusion}

Marcello Malpighi, the Italian physician and anatomist (1628-1694), is regarded by many as the founder of microscopic anatomy. His treatise on the internal organs of the silkworm was the first monograph on an invertebrate. He described insect air sacs and the tracheal system as well as the tubules that now bear his name $[35,36]$. Malpighi would be interested that over 300 years on there is still at lot to learn about the insect excretory tubules named after him.

\section{Acknowledgments}

The authors would like to thank Max Barclay and Mick Webb from the Entomology Department of the Natural History Museum, London, for their helpful advice.

\section{References}

[1] T. Hörnschemeyer, R. G. Beutel, and F. Pasop, "Head structures of Priacma serrata leconte (Coleptera, Archostemata) inferred from X-ray tomography," Journal of Morphology, vol. 252, no. 3, pp. 298-314, 2002.

[2] M. K. Greco, R. N. Spooner-Hart, and P. Holford, "A new technique for monitoring Trigona carbonaria nest contents, brood and activity using X-ray computerized tomography," Journal of Apicultural Research, vol. 44, no. 3, pp. 97-100, 2005.

[3] D. Grimaldi and M. S. Engel, Evolution of the Insects, Cambridge University Press, Cambridge, UK, 2005.

[4] M. K. Greco, R. N. Spooner-Hart, G. A. C. Beattie, I. Barchia, and P. Holford, "Australian stingless bees improve greenhouse
Capsicum production," Journal of Apicultural Research, vol. 50, no. 2, pp. 102-115, 2011.

[5] M. K. Greco, D. Hoffmann, A. Dollin, M. Duncan, R. N. Spooner-Hart, and P. Neumann, "The alternative Pharaoh approach: stingless bees mummify beetle parasites alive," Naturwissenschaften, vol. 97, no. 3, pp. 319-323, 2010.

[6] M. K. Greco, M. Bell, R. N. Spooner-Hart, and P. Holford, "Xray computerized tomography as a new method for monitoring Amegilla holmesi nest structures, nesting behaviour, and adult female activity," Entomologia Experimentalis et Applicata, vol. 120, no. 1, pp. 71-76, 2006.

[7] M. K. Greco, A. Jones, R. N. Spooner-Hart, and P. Holford, "X-ray computerised microtomography (MicroCT): a new technique for assessing external and internal morphology of bees," Journal of Apicultural Research, vol. 47, no. 4, pp. 286291, 2008.

[8] J. Al-Harbi, V. Hunt, K. Charnley, D. Heatley, G. D. Bell, and N. Corps, "X-ray microCT enables high-resolution 3-D imaging of the internal anatomy of live locusts," Poster presentation at the World Congress of Entomology, South Africa http:// www.fishersideas.co.uk/Papers/WorldCongressOnEntomologyJuly08.pdf.

[9] M. S. Engel, "Systematic melittology: where to from here?" Systematic Entomology, vol. 36, no. 1, pp. 2-15, 2011.

[10] M. K. Greco, P. M. Welz, M. Siegrist et al., "Description of an ancient social bee trapped in amber using diagnostic radioentomology," Insectes Sociaux, vol. 58, no. 4, pp. 487-494, 2011.

[11] M. K. Greco, J. Tong, M. Soleimani, G. D. Bell, and M. O. Schaefer, "Imaging live bee brains using minimally-invasive diagnostic radioentomology," Journal of Insect Science. In press.

[12] V. B. Wigglesworth, "Excretion," in Insect Physiology (Methuen's Monographs on Biological Subjects), chapter 5, pp. 5669, 4th edition, 1950.

[13] B. A. Marcus, "malpighian tubules: Coleoptera," Zoologica Morphology and Oekology, Tiere, vol. 19, pp. 609-677, 1930.

[14] S. H. P. Maddrell, "The mechanisms of insect excretory systems," Advances in Insect Physiology, vol. 8, no. C, pp. 199$331,1972$.

[15] A. D. Imms, O. W. Richards, and R. G. Davies, "The excretory organs, fat body and other haemocoelic structures," in Imms' General Textbook of Entomology, O. W. Richards and R. G. Davies, Eds., vol. 1, chapter 15, pp. 248-262, Chapman and Hall, London, UK, 10th edition, 1977.

[16] D. M. Bell, Studies on the malpighian tubules of Locusta migratoria migratorioides $(R+F)$, with particular reference to the role of $\mathrm{Na}^{+}-\mathrm{K}^{+}$activated ATPase in fluid secretion, a thesis submitted for the degree of Doctor of Philosophy, University of Durham, January 1977.

[17] D. M. Bell and J. H. Anstee, "A study of the Malpighian tubules of Locusta migratoria by scanning and transmission electron microscopy," Micron, vol. 8, no. 3, pp. 123-134, 1977.

[18] J. H. Anstee, D. M. Bell, and D. Hyde, "Some factors affecting Malpighian tubule fluid secretion and transepithelial potential in Locusta migratoria L.," Experientia, vol. 36, no. 2, pp. 198199, 1980.

[19] M. J. Klowden, “The excretory system," in Physiological Systems in Insects, chapter 8, pp. 403-432, Elsevier, Amsterdam, The Netherlands, 2nd edition, 2007.

[20] J. L. Nation, "Excretion," in Insect Physiology and Biochemistry, chapter 17, pp. 417-446, Taylor \& Francis, Boca Raton, Fla, USA, 2nd edition, 2008. 
[21] I. Hodek, "Adult diapause in Coleoptera," Psyche, vol. 2012, Article ID 249081, 10 pages, 2012.

[22] L. Woolnough, Understanding and Using the Stereomicroscope, Quekett Microscopical Club c/o The Natural History Museum, London, UK, 2010.

[23] M. Tarplee and N. Corps, "Skyscan 1072 Desktop X-ray microtomograph—sample scanning, reconstruction, analysis and visualization (2-D \& 3-D) protocols. Guidelines, notes, selected references and F.A.Q," 208, http://www.geog.qmul.ac .uk/docs/staff/4952.pdf.

[24] P. J. Gullen and P. S. Cranston, 'The Insects' an Outline of Entomology, Blackwell, 2000.

[25] I. D. Green, G. Merrington, and M. Tibbett, "Transfer of cadmium and zinc from sewage sludge amended soil through a plant-aphid system to newly emerged adult ladybirds (Coccinella septempunctata)," Agriculture, Ecosystems and Environment, vol. 99, no. 1-3, pp. 171-178, 2003.

[26] I. D. Green, C. Jeffries, A. Diaz, and M. Tibbett, "Contrasting behaviour of cadmium and zinc in a soil-plant-arthropod system," Chemosphere, vol. 64, no. 7, pp. 1115-1121, 2006.

[27] M. Tam, G. D. Bell, S. Williams, and D. Heylings, "Making cross-sectional anatomy an accessible adjunct for anatomy education," Clinical Anatomy, vol. 20, no. 4, pp. 465-472, 2007.

[28] M. D. Tam, A. R. Hart, S. Williams, D. Heylings, and S. Leinster, "Is learning anatomy facilitated by computer-aided learning? A review of the literature," Medical Teacher, vol. 31, no. 9, pp. e393-e396, 2009.

[29] M. D. B. S. Tam, A. R. Hart, S. M. Williams, R. Holland, D. Heylings, and S. Leinster, "Evaluation of a computer program ("disect") to consolidate anatomy knowledge: a randomisedcontrolled trial," Medical Teacher, vol. 32, no. 3, pp. e138-e142, 2010.

[30] S. Smith, D. Rae, R. S. Rowland, R. Lapeer, and G. D. Bell, "Experience with a laptop-based 3-D DICOM reader at MDT meetings in a DGH," Gut, vol. 53, supplement 3, 2004.

[31] D. J. T. Heatley, R. S. Rowland, G. D. Bell et al., "The networking capabilities of a laptop-based 3D DICOM viewer to facilitate multi-site MDTs," Gut, vol. 54, supplement 11, article A76, 2005.

[32] D. J. T. Heatley, R. S. Rowland, G. D. Bell et al., "A new laptopbased DICOM viewer for in-theatre procedures, multi-site MDT meetings and networked training," in Proceedings of the HC Conference, Harrogate, UK, March 2006.

[33] S. L. Smith, P. Fleming, S. Girling et al., "Life without PACS: further experience with an inexpensive PC-based networked 3-D DICOM viewer," in Proceedings of the UKRC Conference, pp. 54-55, May 2006.

[34] B. A. Smith, G. D. Bell, D. J. T. Heatley et al., "Life without PACS: further experience with an inexpensive PC-based networked 3-D DICOM viewer," in Proceedings of the UKRC Conference, pp. 54-55, May 2006.

[35] Chambers, Chamber's Dictionary of Scientists: By A. V. Howard, Chambers, 1961.

[36] B. J. Ford, The Optical Microscope Manual, David and Charles, 1973. 

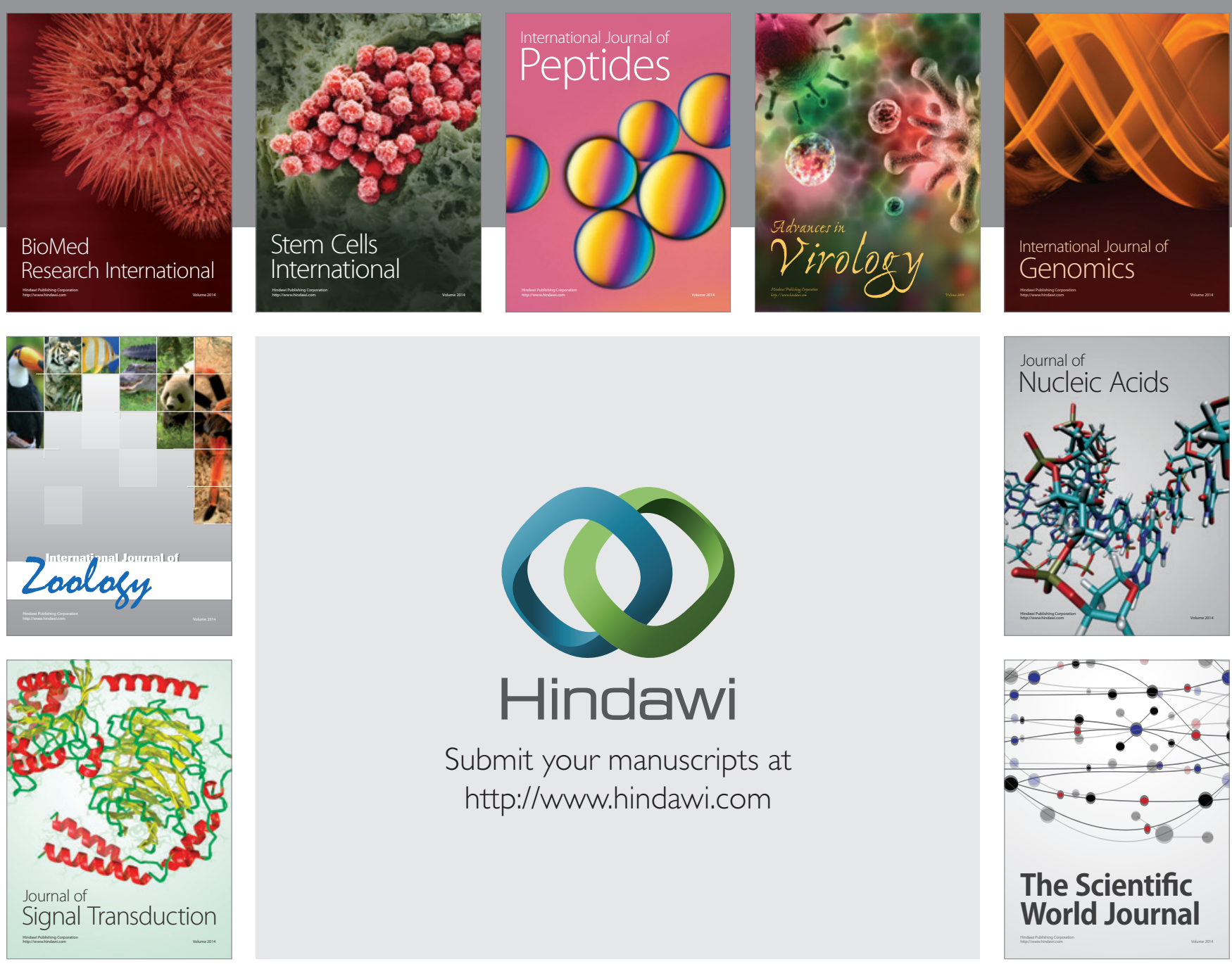

Submit your manuscripts at

http://www.hindawi.com
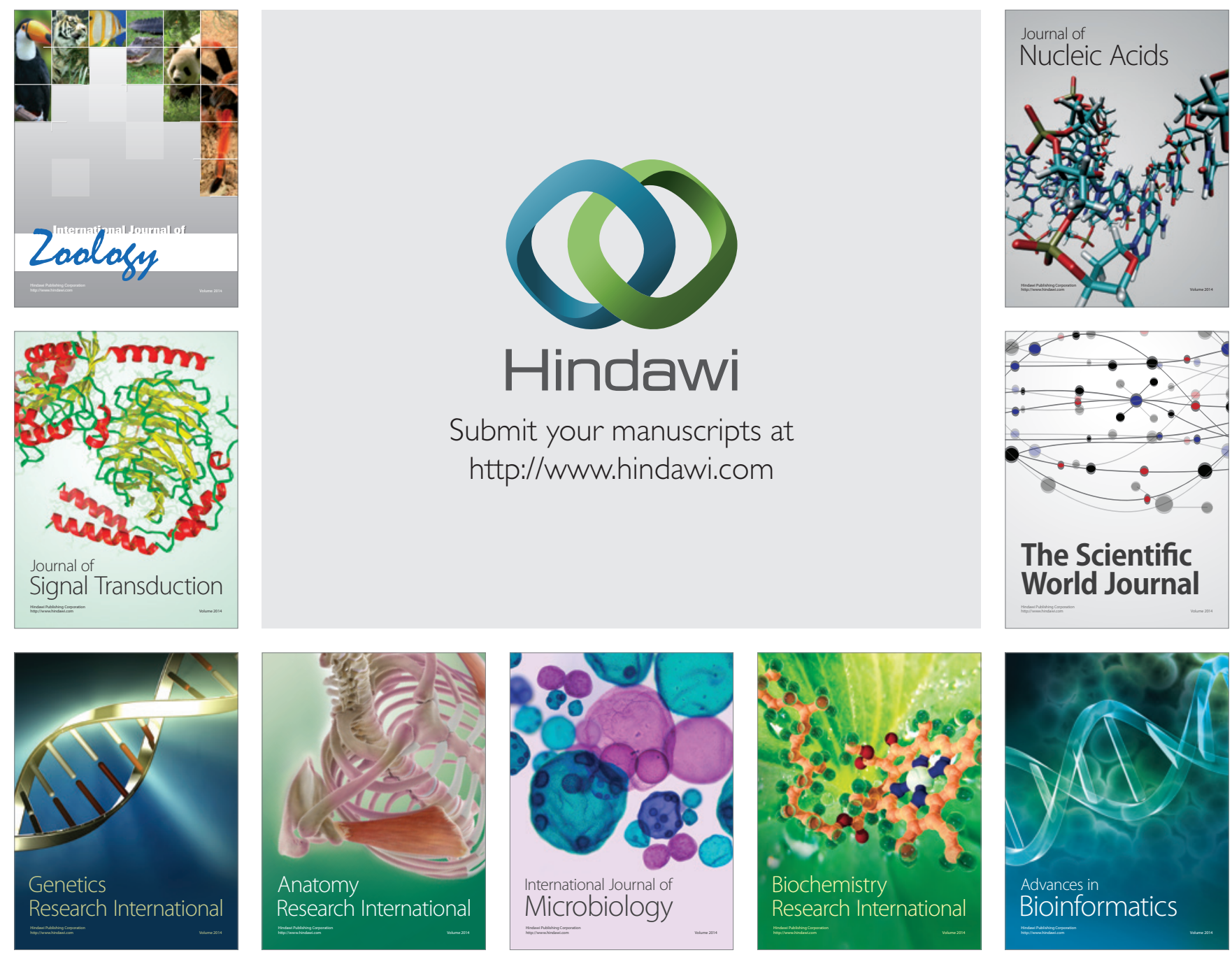

The Scientific World Journal
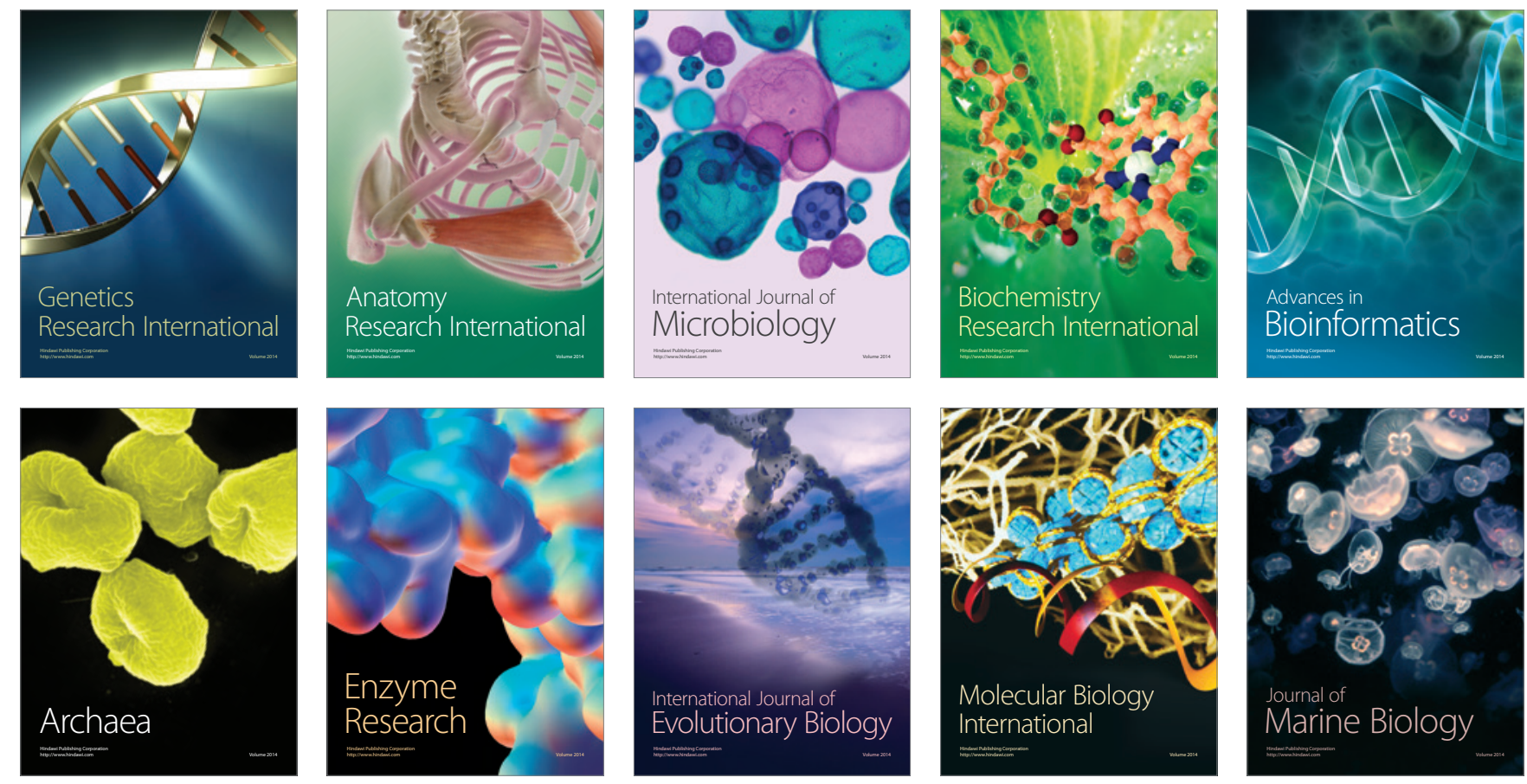